\title{
Ruangan Kelas dan Laboratorium Pintar (Menuju Smart Campus dengan Internet of Things)
}

\author{
Smart Classroom and Laboratory \\ (Towards Smart Campus with Internet of Things)
}

\author{
Rahmat Fanshuri, Wiwik Wiharti, Firdaus \& Ihsan Lumasa Rimra \\ Jurusan Teknik Elektro Politeknik Negeri Padang Kampus Limau Manis Padang 25163 \\ Telp. 0751-72590 Fax. 0751-72576 Email: rahmatfanshuri@ gmail.com, \\ wiwikwiharti@pnp.ac.id, mrdauz@pnp.ac.id \& rimra@pnp.ac.id
}

\begin{abstract}
Smart Classroom and Laboratory (SCL) is one of technologies that can be implemented to empower the availability of Information and Communication Technologies (ICT) infrastructure. All devices and components in class and labor will become entities that are integrated and embedded into electronic devices in order to make them to behave as the Internet of Things (IoT). SCL is used to assist lecturers in monitoring and managing classrooms and laboratories in real time. Moreover, the classroom / laboratory will be smarter because the lighting and cooling systems are made to adapt according to the number of people in the room.
\end{abstract}

Keywords : ICT, IoT, Smart Classroom and Laboratory

\section{PENDAHULUAN}

Di era millenial, sebagian besar perguruan tinggi baik di Indonesia maupun di dunia memiliki visi menjadi World Class University (WCU). Salah satu indikator menuju WCU adalah kampus harus mempunyai infrastruktur Information and Communication Technology (ICT) yang komprehensif dan memadai (Dlamini 2017; Arpan 2015; Hsing 2013; Majeed 2018). Khusus di Indonesia, hal ini juga sejalan dengan keinginan pemerintah untuk meningkatkan daya saing bangsa Indonesia di kancah internasional. Infrastruktur ICT pun sekarang juga telah menjadi salah satu indikator kualitas perguruan tinggi di Indonesia.

Salah satu teknologi yang dapat diimplementasikan untuk memberdayakan ketersediaan infrastruktur ICT adalah penerapan teknologi Smart Campus (SC) atau Intelligent Campus (iCampus) atau Digital Campus (DC) atau Kampus Pintar (Chuling 2009; Heinemann 2018; Mainetti 2011; Wang 2017; Wardani 2017; Zahariev 2013). Semua perangkat dan komponen yang ada di kampus akan menjadi entiti yang diintegrasikan dan ditanamkan ke perangkat elektronik sehingga akan berbentuk objek yang pintar atau Smart Objects atau (Internet of Things/ IoT) (Atzori 2010; Castellani 2010; Gubbi 2013; Scarfo 2014; Want 2015).

Khusus untuk sistem pengelolaan dan pemantauan ruangan kelas dan laboratorium melalui teknologi Smart Classroom and Laboratory (SCL) yang merupakan bagian dari SC, sampai saat ini Politeknik Negeri Padang belum memaksimalkan penggunaan infrastruktur ICT yang ada. Dengan SCL ini akan dapat dilakukan pemantauan dan pengelolaan ruangan kelas dan laboratorium secara real time karena sistem ini secara keseluruhan akan terintegrasi pada suatu sistem yang lebih besar dan dapat diakses melalui satu jaringan dan platform dan juga memberikan efisiensi terhadap pemakaian listrik khususnya untuk sistem pencahayaan ruangan (Wiharti, 2016). 
Dosen akan dapat mengetahui siapa dan berapa mahasiswa yang sudah hadir (karena ruangan kelas/ lab dilengkapi dengan sistem absensi sidik jari) atau dosen akan dapat mengetahui apakah mahasiswa sudah berada di kelas/ lab atau dosen dapat memonitor kegiatan yang dilakukan mahasiswa di kelas/ lab. Terlebih dari itu, SCL ini akan dapat membuat ruangan kelas/ lab menjadi lebih pintar karena sistem penerangan dan pendingin di ruang kelas/ lab dibuat dapat beradaptasi sesuai dengan banyaknya orang yang berada dalam ruangan tersebut (yang disesuaikan juga dengan akumulasi perhitungan absen sidik jari mahasiswa pada ruangan tersebut).

Rumusan masalah SCL ini yaitu:

1. Bagaimana menerapkan system IoT dalam ruangan kelas yang mampu memonitoring ruangan, mengontrol fasilitas (AC, Lampu dan InFocus) dalam kelas via wireless.

2. Bagaimana menerapkan Sistem Absensi menggunakan Fingerprint yang dapat di akses melalui internet.

3. Bagaimana proses komunikasi yang terjadi antara microcontroller dengan raspberry pi dan raspberry pi dengan computer.

4. Bagaimana merancang suatu system yang memiliki data up to date dan memperoleh informasi secara real time.

\section{METODOLOGI}

Metodologi yang dilakukan adalah metode penelitian. Metode penelitian dalam pembuatan program ini ada tiga metode, yaitu :

1. Metode penelitian studi literature Penelitian dengan menggunakan media internet dan media cetak. Media internet dapat berupa jurnal, E-Book. Sedangkan media cetak dapat berupa buku-buku materi.

2. Metode penelitian studi Eksperimen Penelitian dengan menggunakan software dan hardware yang di rancang kinerjanya, lalu dilakukan pengujian terhadap pembuatan aplikasi. Setelah itu dilanjutkan dengan melakukan analisis terhadap aplikasi tersebut, apakah aplikasi sudah sesuai dengan yang diinginkan atau belum. Jika hasil sudah sesuai dengan yang diharapkan maka akan disimpulkan hasil yang didapatkan.

3. Metode penelitian sendiri adalah peraturan atau prosedur yang digunakan oleh seorang programmer untuk melakukan kegiatan secara disiplin. Dalam penelitian setiap orang dipengaruhi oleh tujuan serta profesi dari masing-masing pengguna.

\section{Definisi Smart Classroom and Laboratory (SCL)}

Smart Classroom and Laboratory (SCL) sebagai bagian dari SC merupakan penerapan penataan dan pemantauan ruangan kelas/ laboratorium yang memberikan informasi secara real time karena sistem ini secara keseluruhan akan terintegrasi pada suatu sistem yang lebih besar dan dapat diakses melalui satu jaringan dan platform.

Dosen akan dapat mengetahui siapa dan berapa mahasiswa yang sudah hadir (karena ruangan kelas/ lab dilengkapi dengan sistem absensi sidik jari) atau dosen akan dapat mengetahui apakah mahasiswa sudah berada di kelas/ lab atau dosen dapat memonitor kegiatan yang dilakukan mahasiswa di kelas/ lab.

Terlebih dari itu, SCL ini akan dapat membuat ruangan kelas/ lab menjadi lebih pintar karena sistem penerangan dan pendingin di ruang kelas/ lab dibuat dapat beradaptasi (Khan 2016; Pan 2015; Wiharti 2016) sesuai dengan banyaknya orang yang berada dalam ruangan tersebut (yang disesuaikan juga dengan akumulasi perhitungan absen sidik jari mahasiswa pada ruangan tersebut).

\section{Definisi Raspberry Pi}

Raspberry Pi adalah sebuah komputer single-board yang dibuat oleh Raspberry Pi Foundation, sebuah amal dibentuk dengan 
tujuan utama untuk diperkenalkan kembali keterampilan komputer tingkat rendah untuk anak-anak di Inggris. Nama Raspberry Pi dikombinasikan dari keinginan untuk menciptakan sebuah alternatif fruit-based computer (seperti Apple, Blackberry, dan Apricot) dan sebuah persetujuan dari konsep original, komputer sederhana yang dapat di program menggunakan Python (disingkat Pi).

\section{Proses Identifikasi Wajah}

Face recognition merupakan salah satu bagian dari pengolahan citra yang digunakan untuk membandingkan satu citra wajah masukan dengan suatu database wajah kemudian menghasilkan data wajah yang sesuai dengan citra tersebut.

pada tahapan Proses Identifikasi Wajah dilakukan pengukuran kemiripan antara citra masukan dengan citra yang sudah disimpan dalam database. Hal yang cukup sulit dari system pendeteksian dan pengenalan wajah adalah bagaimana membuat sebuah system pendeteksi dan pengenalan wajah yang cepat atau mendekati waktu nyata dan memiliki tingkat akurasi yang tinggi.

\section{Web Server}

Web server adalah sebuah aplikasi server yang melayani permintaan HTTP atau HTTPS dari browser dan mengirimkannya kembali dalam bentuk halaman-halaman web. Halaman-halaman web yang dikirim oleh web server biasanya berupa file-file Hyper Text Markup Language (HTML) dan Cascading Style Sheet (CSS) yang nantinya akan di parsing atau ditata oleh browser sehingga menjadi halaman-halaman web yang bagus dan mudah dibaca. Cara kerja dari web server sebenarnya sangat mudah dipahami. Proses yang akan terjadi pada browser adalah browser akan membentuk koneksi dengan web server, meminta halaman website dan menerimanya . Web server kemudian mengecek permintaan tersebut apakah tersedia atau tidak. Apabila tersedia, maka web server akan mengirimkan data kepada browser.

\section{Perancangan}

Smart Classroom And Laboratory yaitu sistem otomatis yang dapat memudahkan pengguna untuk me monitoring ruangan, Absensi, mengontrol pencahayaan, mengendalikan AC dan InFocus, serta dilengkapi dengan sebuah alarm yang dapat memberikan peringatan jika terjadi kebakaran di dalam ruangan tersebut, seorang user harus terhubung dalam jaringan internet untuk dapat mengakses hasil kerja dari alat, Hasil kerja alat ditampilkan pada halaman web yang mana informasi yang diperoleh web berasal dari kerja alat yang di pasang dalam ruangan. Untuk pengendalian sistem secara keseluruhan di gambarkan pada Gambar 1 Blok diagram Smart Classroom and Laboratory.

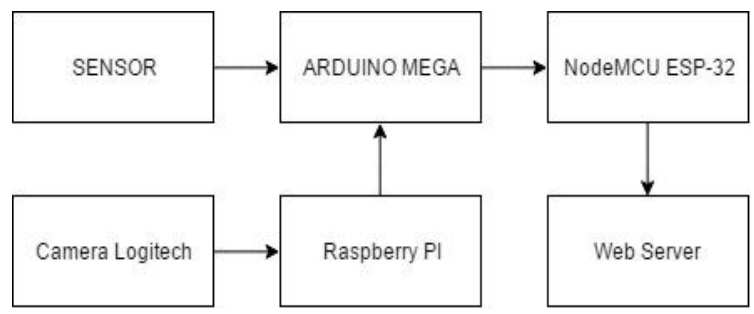

Gambar 1. Blok diagram Smart Classroom and Laboratory.

Gambar 1 merupakan perancangan sistem hardware yang dibangun meliputi tiga komponen pengontrolan yaitu Raspberry Pi, Arduino Mega, NodeMCU, Raspberry akan mengambil video melalui camera webcam dan membaginya kedalam jaringan, serta hasil rekaman tersebut akan ditampilkan ke dalam Web Server, Raspberry pi juga akan mendeteksi keberadaan manusia dengan kamera dengan prinsip face recognition artinya jika wajah manusia terdeteksi dalam ruangan maka raspberry akan memberitahukan kepada arduino bahwa ada manusia dalam raungan dengan mengirimkan karakter tertentu, arduino dan raspberry pi terhubung melalui kabel USB (Port Serial). Arduino akan 
mengaktifkan relay yang terhubung dengan lampu jika terdeteksi manusia dalam ruangan dan menghidupkan lampu.

\section{Flowchart Sistem}

Sensor pendeteksi suhu, asap dan fingerprint aktif secara terus menerus pada ruangan selama terhubung ke listrik. Sensor DHT11 yang dapat mengukur suhu dan kelembapan di udara sekitarnya. Sensor asap digunakan untuk mendeteksi kebakaran dalam ruangan dengan cara mengukur kadar gas dalam ruangan.

Gas yang dapat dideteksi diantaranya : $L P G$, i-butane, propane, methane, alcohol, Hydrogen, smoke. Pada saat sensor DHT11, Fingerprint dan MQ6 di ruangan menerima rangsangan maka akan di kirim notifikasi ke web, selain notifikasi ke web perangkat juga akan memberikan respons berupa alarm atau penanda bila sensor-sensor tersebut digunakan atau kondisinya terpenuhi.

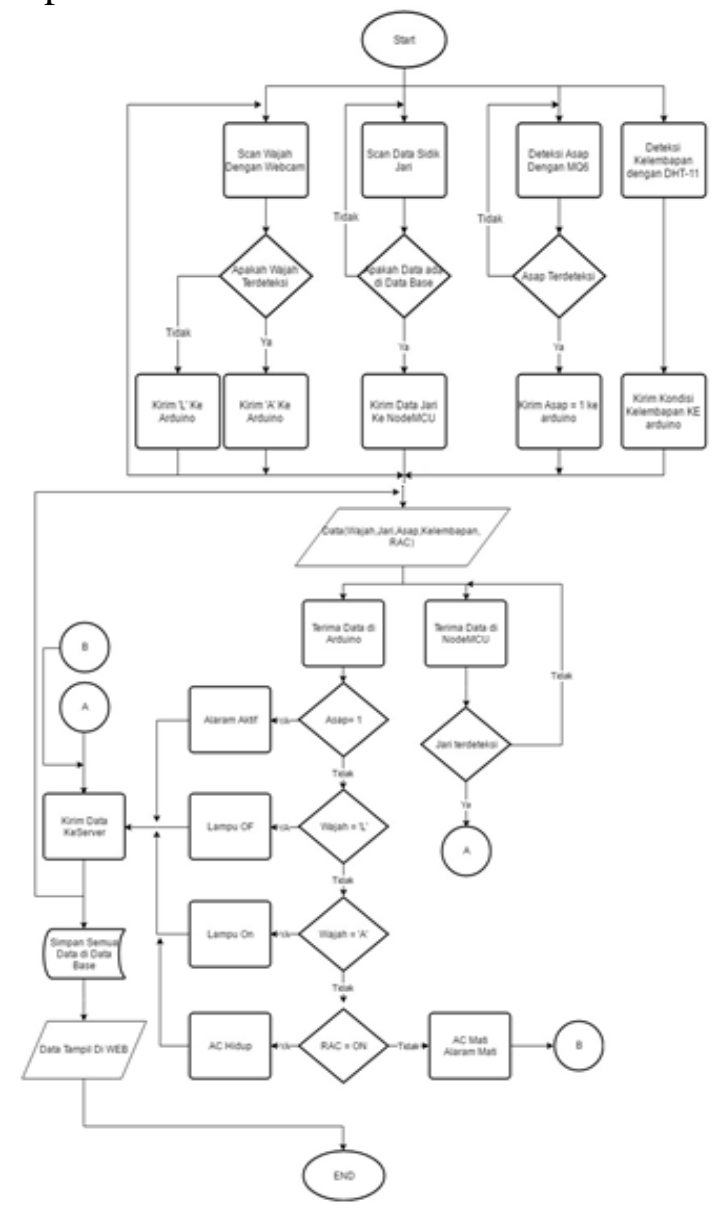

Gambar 2. Flowchart Sistem Smart Classroom And Laboratory
Selain fungsi pembaca kondisi ruangan (sensor) alat juga akan melakukan pengontrolan perangkat dengan menggunakan sinyal infrared kepada perangkat dengan menghidup-matikan lampu, ac, dan InFocus, baik dikontrol secara otomatis maupun manual. Untuk proses sistem notifikasi dari nodemcu ke web dilakukan dengan cara nodemcu mengirim data ke database server. Sistem ini bekerja dengan cara seperti yang ditunjukkan Flowchart pada Gambar 2 di samping.

Flowchart di atas merupakan alur kerja perangkat hardware, selain perangkat bekerja secara hardware perangkat ini juga di dukung oleh software berupa halaman web yang dapat di akses oleh user, adapun flowchart software di gambarkan seperti Gambar 3 berikut :

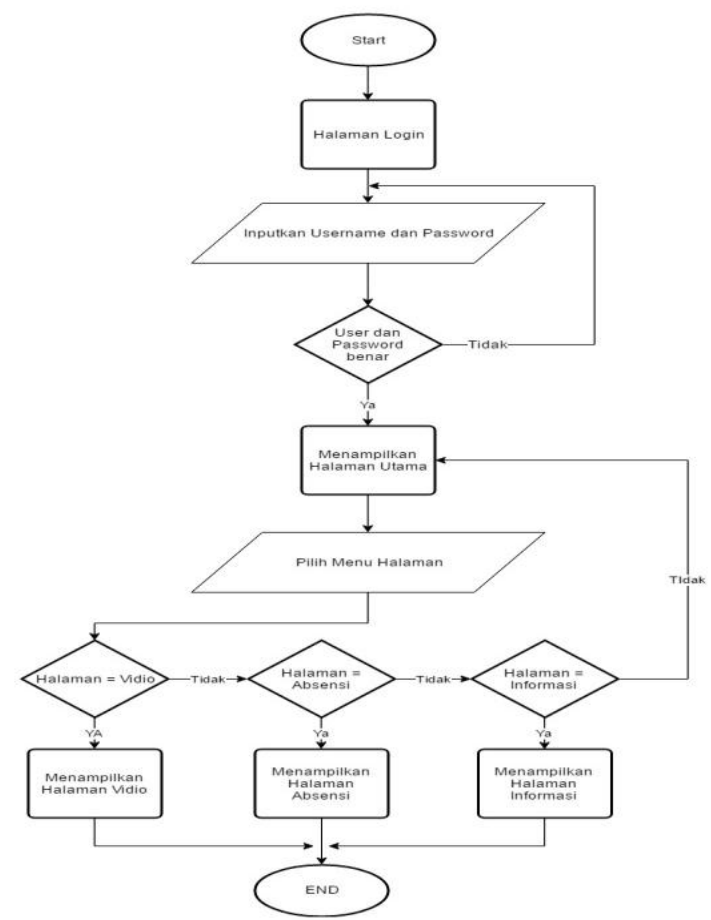

Gambar 3. Flowchart sistem aplikasi berjalan

Perancangan web server pada internet

Koneksi antara Raspberry $\mathrm{Pi}$ dan NodeMCU dengan web server mengagunkan protocol HTTP. Data yang dikirim oleh alat akan di upload ke database server. Selanjutnya informasi akan dapat di akses oleh user melalui web seperti yang di tunjukan Gambar 4. 


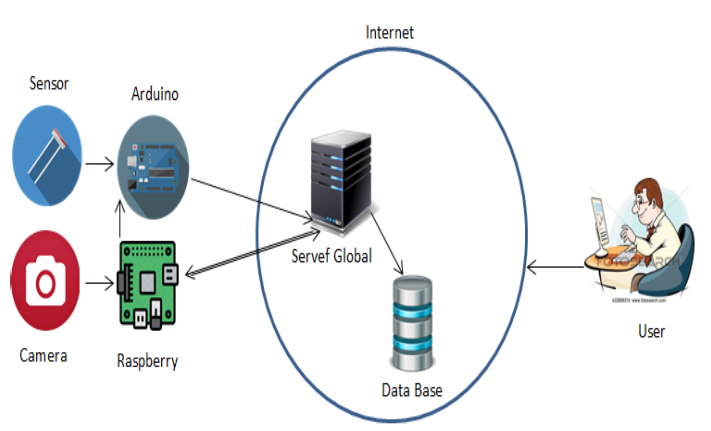

Gambar 4. Akses HTTP Protokol Client-server

\section{Perancangan Layout User Interface}

Perancangan interface dilakukan untuk menentukan bentuk fisik dari tampilan web yang menampilkan bentuk tampilan halaman login, layout utama, halaman utama, halaman layout video dan halaman layout informasi. Rancangan layout utama pada merupakan tampilan login agar dapat mengakses halaman utama dari web Smart Classroom And Laboratory.

Pada halaman ini user harus memasukkan ID dan password yang benar agar user dapat masuk ke halaman utama dari web Smart Classroom and Laboratory.

Pada halaman layout utama ini user akan diperlihatkan apa saja fitur atau fungsi yang dapat dijalankan perangkat.

Pada halaman absensi user dapat melihat daftar kehadiran mahasiswa yang hadir pada saat itu ataupun yang hadir di hari-hari sebelumnya. Di halaman tersebut user dapat memilih tanggal kapan daftar absennya.

Pada halaman video, user dapat melihat kondisi ruangan dan dapat melakukan monitoring, video yang ditampilkan berupa video real time kondisi ruangan saat itu. Berikut adalah tampilan halaman video pada web pada saat alat tidak dinyalakan dan video tidak sedang streaming.

Sementara, pada halaman informasi ini user dapat melihat beberapa variable yaitu dapat memantau jumlah orang dalam ruangan, mengetahui suhu dan kelembapan ruangan, mengetahui kondisi dari perangkat yang ada di ruangan (AC, Lampu, InFocus) dan yang terpenting dapat mengetahui kondisi ruangan jika terjadi kebabaran. Berikut adalah tampilan dari menu informasi.

\section{Perancangan Hardware}

Perancangan perangkat keras (hardware) meliputi perancangan mekanik dan elektronik.

\section{Perancangan Mekanik}

Pada perancangan system ini di rancang sebuah mekanik yang secara tampilan terdiri dari tiga buah kotak yang disusun bertingkat.kotak pertama digunakan untuk tempat peletakan kotak 2 dan 3, berikut adalah tampilan kotak 1 dan 2 .

Pada kotak kedua tersebut memiliki fungsi sebagai tempat peletakan raspberry , relay, dan adaptor untuk supply tegangan pada perangkat. Untuk kotak ketiga berupa kotak yang di bentuk menyerupai sebuah robot, dimana pada kotak ketiga inilah sensor-sensor di hubungkan dengan mikrokontroler, berikut adalah tampilan dari kotak ketiga.

Dari keseluruhan kotak tersebut akan disusun sehingga akan menghasilkan perangkat secara keseluruhan sehingga perangkat dapat di fungsikan berikut adalah tampilan keseluruhan perangkat beserta keterangan posisi-posisi sensor yang di pasang pada perangkat. 


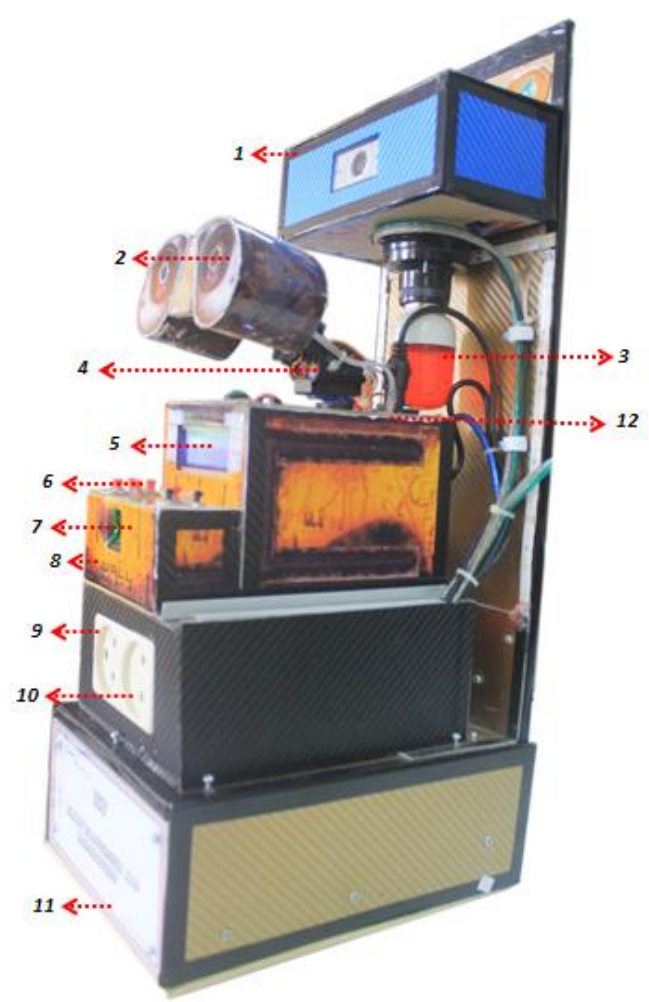

Gambar 5. Tampak keseluruhan perangkat

Keterangan dari Gambar 5 di atas adalah sebagai berikut:

1. Posisi camera webcam.

2. Posisi sensor pendeteksi Asap (MQ-6).

3. Lampu alarm.

4. Servo penggerak .

5. Lcd 16x2 untuk menampilkan menu system.

6. Tombol yang digunakan untuk memilih menu.

7. Posisi sensor fingerprint.

8. Kotak 3, tempat peletakan mikrokontroler.

9. Kotak 2, tempat peletakan Raspbrry pi.

10. Konektor AC untuk dihubungkan dengan lampu ruangan.

11. Kotak 1, sebagai kedudukan dari kotak 2 dan 3.

12. Posisi sensor kelembapan (DHT-11).

\section{Cara pengoperasian alat} berikut

Alat dioperasikan dengan cara sebagai

1. Menghubungkan Kabel Power ke sumber
2. Memastikan kabel data untuk arduino dan NodeMCU sudah terhubung dengan benar.

3. Menekan tombol power arduino dan raspberry pi yang terpasang pada alat.

4. Menunggu sekitar 40 detik untuk alat mengeksekusi programnya.

5. Menekan tombol reset NodeMCU, agar NodeMCU terhubung kedalam jaringan. Dan perangkat akan bekerja sesuai fungsinya.

\section{HASIL DAN PEMBAHASAN}

Setelah melakukan serangkaian percobaan, didapatkan beberapa hasil terhadap pengujian beberapa sensor-sensor yang digunakan.

Pengujian sensor DHT11 dilakukan untuk mengetahui apakah sensor DHT11 dapat bekerja baik dalam membaca suhu dan kelembapan dalam ruangan, serta mengetahui apakah sensor DHT11 dapat merespons dengan baik ke arduino mega 2560. Pengujian ini dilakukan pada siang hari, sehingga didapat data seperti pada Gambar 6.

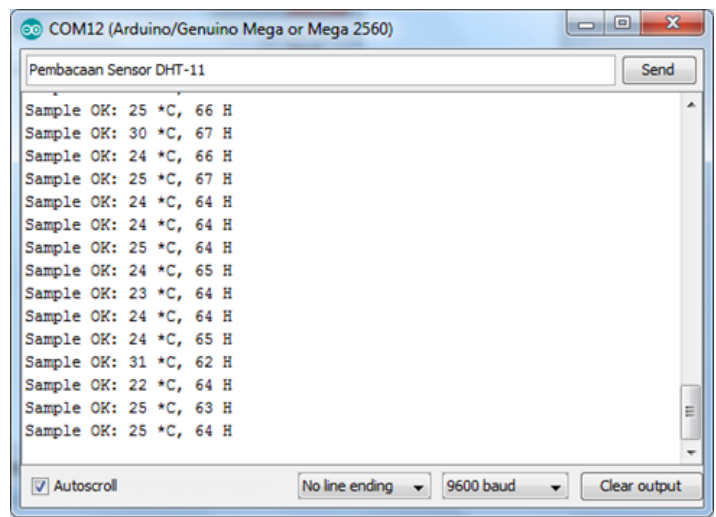

Gambar 6. Hasil Bacaan Suhu dan Kelembapan

Dari hasil pengujian sensor DHT11 dapat diperoleh besarnya kondisi suhu pada saat pengujian adalah $\pm 25^{\circ} \mathrm{C}$ dengan kadar humidity 64, humidity ini menunjukkan banyak uap air pada udara sekitar.

Sementara itu, untuk pengujian sensor MQ-6 dilakukan untuk mengukur kadar asap, LPG dan CO dalam ruangan dengan tujuan untuk mendeteksi kebakaran, pada 
saat pengujian dengan kondisi ruangan tidak ada asap. Pada hasil pengujian normal terlihat tiga unsur LPG,CO and SMOKE memiliki nilai nol hal ini terjadi karena pada saat pengujian tidak ada asap di sekitar perangkat, dari ketiga faktor inilah yang nantinya perangkat akan mendeteksi api di dalam ruangan, biasanya api akan mengandung ke tiga unsur tersebut. Saat pengujian mendeteksi api dengan MQ-6 menghasilkan data seperti Gambar 7 .

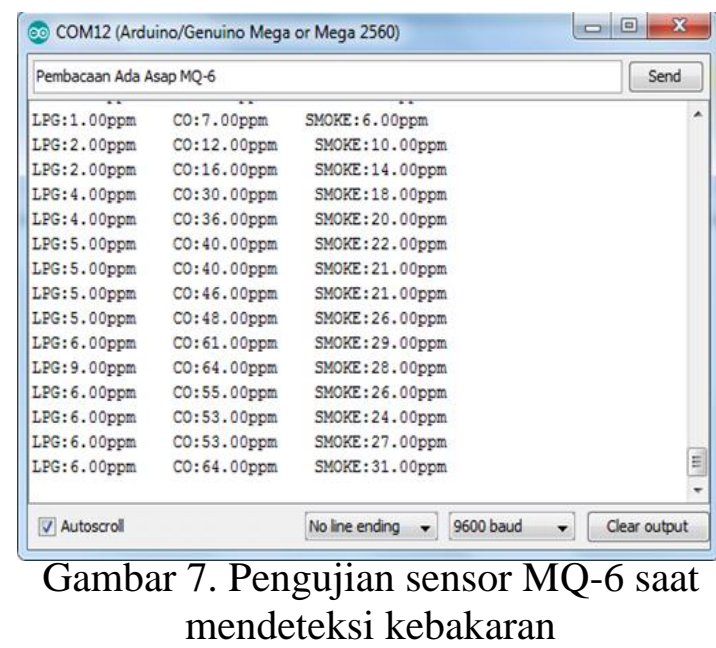

Dari hasil pengujian membuktikan sensor MQ-6 bekerja dengan optimal saat mendeteksi kebakaran, pada saat di lakukan pembakaran di dekat perangkat, MQ-6 langsung memberikan pembacaan yang akurat terhadap kondisi tiga unsur (LGP, $\mathrm{CO}$ dan asap) hasil perubahan unsur inilah yang akan menjadi pedoman pada perangkat untuk mengetahui terjadinya kebakaran.

\section{SIMPULAN}

Berdasarkan Pembahasan yang sudah dijelaskan sebelumnya maka kesimpulan yang dapat diambil sebagai berikut :

1. Perancangan Smart Classroom and Laboratory khusus untuk pembacaan suhu, kelembapan dan kebakaran dengan menggunakan Raspberry pi, NodeMCU, Arduino Mega berhasil diterapkan.
2. Hasil pembacaan suhu dan kelembapan menunjukkan bahwa peralatan dapat berjalan dengan baik.

3. Sensor MQ6 juga dapat bekerja dengan baik dalam memberikan notifikasi jika terjadi kebakaran.

\section{DAFTAR PUSTAKA}

Adamko A et al, 2018. Smart campus service link: Adaptation and interaction planes for campus and university environments. 28th IEEE International Conference on Cognitive Infocommunications (CogInfoCom), pp 271-276.

Apcar, J. 2011. IP in Smart Object Networks. Hongkong: Cisco Systems.

Castellani, A. et al. 2010. Architecture and Protocols for the Internet of Things: A Case Study. 678-683.

Centenaro, M., L. Vangelista, A. Zanella, and M. Zorzi. 2016. Long-range communications in unlicensed bands: the rising stars in the IoT and smart city scenarios. IEEE Wirel. Commun., vol. 23, no. 5, pp. 60-67.

Khan, M., B. N. Silva, and K. Han. 2016. Internet of Things based Energy Aware Smart Home Control System. IEEE Access, vol. 3536, no. c, pp. 11.

Pan $J$ et al 2015. An Internet of things framework for smart energy in buildings: designs, prototype, and experiments. IEEE Internet of Things Journal, vol. 2, no. 6, pp. 527-537.

Rimra, IL., Andrizal, Firdaus, \& Wiharti, W. 2012. Pemodelan Customer Premise Equipment (CPE) untuk Internet Protocol versi 6 (IPv6). Padang: Politeknik Negeri Padang.

Suyadi 2012. Komunikasi Serial dan Port Serial (COM) L200100015, Teknik Informatika UMS. 
Tim Cox. 2014. Raspberry Pi Cookbook for Python Programmers. Edition 1. Birmingham: Packt Publishing Ltd.

Wiharti W., Novid I., Firdaus, and Rimra IL. 2016. Smart Grid Test Bed Implementation in Controlling the Lighting System on Smart Home Environment. Smart Grid Test Bed Implementation in Controlling the Lighting System on Smart Home Environment. pp. 435-441. 